\title{
PHASE BEHAVIOUR CALCULATIONS FOR THE CARBON DIOXIDE + 1,2-DIMETHOXYETHANE BINARY SYSTEM WITH A CUBIC EQUATION OF STATE
}

\author{
SERGIU SIMAa, RADU C. RACOVIŢA ${ }^{a}$, AUREL CHIRILĂ ${ }^{b}$, \\ DRAGOȘ DEACONU ${ }^{\mathrm{b}}$, VIOREL FEROIU ${ }^{\text {a }}$, CATINCA SECUIANU ${ }^{\mathrm{a}, \mathrm{c}, *}$
}

\begin{abstract}
The ability of different thermodynamic models to predict the phase behaviour of carbon dioxide (1) + 1,2-dimethoxyethane (2) binary system is tested. The model chosen is the General Equation of State (GEOS) coupled with classical van der Waals mixing rules (two-parameter conventional mixing rule, 2PCMR). Comparisons were made with the GEOS3C, Soave-RedlichKwong (SRK), and Peng-Robinson (PR) cubic equations of state (EoS) too. A single set of binary parameters for each model was used to predict correctly the global phase behaviour of the system.
\end{abstract}

Keywords: carbon dioxide, 1,2-dimethoxyethane, high-pressures, vapour-liquid equilibrium, equations of state, GEOS, GEOS3C

\section{INTRODUCTION}

Over $80 \%$ of greenhouse gases (GHGs) are represented by carbon dioxide $\left(\mathrm{CO}_{2}\right)$ which enters the atmosphere through burning fossil fuels such as coal, oil, and natural gas, in power plants and energy production facilities as well as solid waste, trees and other biological materials and also as a result of certain chemical reactions in different industry (e.g., cement industry) [1-3].

a University Politehnica of Bucharest, Faculty of Applied Chemistry and Materials Science, Department of Inorganic Chemistry, Physical Chemistry and Electrochemistry, 1-7 Gh. Polizu Street, S1, 011061 Bucharest, Romania

b University Politehnica of Bucharest, Faculty of Electrical Engineering, Department of Electrical Machines, Drives, and Materials, 313 Spl. Independentei Street, S6, 060042, Bucharest, Romania

c Imperial College London, Department of Chemical Engineering, South Kensington Campus, SW7 2AZ London, United Kingdom,

*Corresponding author: catinca.secuianu@upb.ro; c.secuianu@imperial.ac.uk 
Among the many options for carbon mitigation, carbon capture and storage (CCS) is a vital technology for the cost-effective mitigation of anthropogenic $\mathrm{CO}_{2}$ emissions and could contribute approximately $20 \%$ to $\mathrm{CO}_{2}$ emission reductions by 2050, as recommended by International Energy Agency (IEA) [3,4].

Although CCS holds great potential in many industries and petroleum refineries given their large $\mathrm{CO}_{2}$ emissions, a key obstacle to its utilization on a large scale remains its cost, being both operating and capital costs [3]. The costs of CCS could be reduced for the cases where industrial processes generate rich $\mathrm{CO}_{2}$ gas streams or even pure $\mathrm{CO}_{2}$ but they are still an impediment to its deployment.

In this context, many research focused almost exclusively on the development of improved sorbents with increased $\mathrm{CO}_{2}$ capacity and/or reduced heat of regeneration [5]. However, recent results [3,5] show that whilst equilibrium $\mathrm{CO}_{2}$ capacity is a key determinant of process performance, phase equilibria, transport properties (e.g., viscosity, diffusion coefficients, etc.) and other thermophysical properties (e.g., heat capacity, density, etc.) have a significant effect on the capital cost, and thus on the price of the carbon captured.

Therefore, we recently focused on the phase behaviour research of physical solvent for carbon dioxide capture. Phase equilibria at highpressures of carbon dioxide with different classes of organic substances, such as alkanes [6], cycloalkanes [7,8], alcohols [9-15], ethers [16], esters, ketones, are investigated to illustrate the functional group effect on the solvent ability to dissolve $\mathrm{CO}_{2}$.

As the experiments are usually expensive and very time consuming, equation of state (EoS) models are the most common approach for the correlation and/or prediction of phase equilibria and properties of the mixtures [17].

In this study we focus on the carbon dioxide (1) + 1,2-dimethoxyethane (DME) binary system. DME is an excellent inert aprotic polar solvent, suitable media for a number of chemical reactions. This ether is a clear, colourless, volatile, flammable liquid, fully miscible with water and a range of other substances such as methanol, ethanol, diethyl ether, acetone, tetrahydrofuran (THF), benzene, toluene, etc., and soluble in aliphatic hydrocarbons. It forms chelate complexes with metal cations and acts as a bidentate neutral ligand. The DME molecule is also of interest as it is the smallest element of the polyoxyethylene (POE), the water soluble polymer with various applications in biomedicine. DME is used as a higher boiling alternative to tetrahydrofuran and diethyl ether being an aprotic neutral polar solvent for chemical reactions. It has also multiple utilizations such as a solvent for oligo- and polysaccharides, 
as a solvent for polysilicones, as a low-viscosity component of the solvent for electrolytes of lithium batteries, for etching of PTFE and other fluoropolymers with alkali metal dispersions, as a reaction media in pharmaceutical syntheses, as an entrainer $[18,19]$.

In a previous paper [16], we compared the prediction results by two well-known cubic equations of state (EoS), namely Soave-Redlich-Kwong (SRK) and Peng-Robinson (PR), coupled with both classical van der Waals (2PCMR) and Gibbs excess energy $\left(G^{E}\right)$ mixing rules. A single set of binary interaction parameters for each EoS, determined for the carbon dioxide + 1,2-DME binary system, was used to model the global phase behaviour of the system.

Here, the global phase behaviour of the system was modelled with a general cubic equation of state (GEOS) [20-25] coupled with classical van der Waals mixing rules (2PCMR). This cubic equation is a generalized form with four parameters for all cubic equations of state with two, three, and four parameters. One unique set of binary interaction parameters determined for the carbon dioxide +1,2-DME system was used to calculate the critical curve and vapour-liquid equilibrium diagrams.

\section{MODELLING}

The phase behaviour of this system was modelled with the GEOS equation [20-25] coupled with classical van der Waals mixing rules (2PCMR). The GEOS $[20,21]$ equation of state is:

$$
P=\frac{R T}{V-b}-\frac{a(T)}{(V-d)^{2}+c}
$$

with the classical van der Waals mixing rules

$$
\begin{aligned}
& a=\sum_{i} \sum_{j} X_{i} X_{j} a_{i j} \quad b=\sum_{i} X_{i} b_{i} \\
& c=\sum_{i} \sum_{j} X_{i} X_{j} c_{i j} \quad d=\sum_{i} X_{i} d_{i} \\
& a_{i j}=\left(a_{i} a_{j}\right)^{1 / 2}\left(1-k_{i j}\right) \quad b_{i j}=\frac{b_{i}+b_{j}}{2}\left(1-l_{i j}\right) \quad c_{i j}= \pm\left(c_{i} c_{j}\right)^{1 / 2}
\end{aligned}
$$

with "+" for $c_{i}, c_{j}>0$ and "-" for $c_{i}, c_{j}<0$. Generally, negative values are common for the $c$ parameter of pure components. 
The four parameters $a, b, c$, and $d$ for a pure component are expressed by:

$$
\begin{array}{ll}
a(T)=\frac{R^{2} T_{c}^{2}}{P_{c}} \beta\left(T_{r}\right) \Omega_{a} & b=\frac{R T_{c}}{P_{c}} \Omega_{b} \\
c=\frac{R^{2} T_{c}^{2}}{P_{c}^{2}} \Omega_{c} & d=\frac{R T_{c}}{P_{c}} \Omega_{d}
\end{array}
$$

Setting four critical conditions, with $\alpha_{c}$ as the Riedel criterion:

$$
P_{r}=1 \quad\left(\frac{\partial P_{r}}{\partial V_{r}}\right)_{T_{r}}=0 \quad\left(\frac{\partial^{2} P_{r}}{\partial V_{r}^{2}}\right)_{T_{r}}=0 \quad \alpha_{c}=\left(\frac{\partial P_{r}}{\partial T_{r}}\right)_{V_{r}}
$$

at $T_{r}=1$ and $V_{r}=1$, the expressions of the parameters $\Omega_{a}, \Omega_{b}, \Omega_{c}, \Omega_{d}$ are obtained

$$
\begin{array}{ll}
\Omega_{a}=(1-B)^{3} \quad \Omega_{b}=Z_{c}-B & \Omega_{c}=(1-B)^{2}(B-0.25) \\
\Omega_{d}=Z_{c}-\frac{(1-B)}{2} & B=\frac{1+m}{\alpha_{c}+m}
\end{array}
$$

where $P_{r}, T_{r}, V_{r}$ are the reduced variables and $Z_{c}$ is the critical compressibility factor.

The temperature function used is:

$$
\beta\left(T_{r}\right)=T_{r}^{-m}
$$

The GEOS parameters $m$ and $\alpha_{c}$ were estimated by constraining the EoS to reproduce the experimental vapour pressure and liquid volume on the saturation curve between the triple point and the critical point [23].

We also used GEOS3C equation $[23,24]$ which is based on the GEOS equation $[20,21]$, but with a new temperature function:

$$
\begin{array}{lll}
\beta\left(T_{r}\right)=1+C_{1} y+C_{2} y^{2}+C_{3} y^{3} & \text { for } & T_{r} \leq 1 \\
\beta\left(T_{r}\right)=1+C_{1} y & \text { for } & T_{r}>1 \\
y=1-\sqrt{T_{r}} & &
\end{array}
$$

The $C_{1}, C_{2}$ and $C_{3}$ parameters were obtained by matching points on the saturation curve (vapour pressures together with the corresponding liquid volumes). The objective function for parameters estimation and other details are given elsewhere [24]. 
The calculations were made using the software package PHEQ, developed in our laboratory [26]. The critical curves were calculated using the method proposed by Heidemann and Khalil [27], with numerical derivatives given by Stockfleth and Dohrn [28].

The GEOS equation was used in a semi-predictive approach to obtain a set of binary parameters yielding good results in the binary system carbon dioxide $+1,2-\mathrm{DME}$. The GEOS parameters, critical data, the acentric factors of the pure substances used in the calculations are presented in Table 1 [29].

Table 1. Critical data, acentric factor [29], and GEOS parameters for pure compounds

\begin{tabular}{l|cccccc}
\hline Compound & $T_{\mathrm{c}} / \mathrm{K}$ & $P_{\mathrm{c}} / \mathrm{bar}$ & $V_{\mathrm{c}} / \mathrm{cm}^{3} \cdot \mathrm{mol}^{-1}$ & $\Omega$ & $\alpha_{\mathrm{c}}$ & $m$ \\
\hline $\mathrm{CO}_{2}$ & 304.21 & 73.83 & 93.90 & 0.2236 & 7.0517 & 0.3146 \\
1,2-DME & 536.15 & 38.71 & 271.0 & 0.3475 & 8.7432 & 0.3138 \\
\hline
\end{tabular}

\section{RESULTS AND DISCUSSION}

The first vapour-liquid equilibrium (VLE) and critical curve data of the carbon dioxide $+1,2-\mathrm{DME}$ binary system were recently published [16]. The mentioned study indicated that this system seems to be type I or type II phase behaviour, according to the according to the classification of van Konynenburg and Scott [30] or the more recent one of Privat and Jaubert [31]. Both type I and type II phase behaviour are very similar and they are characterized by a continuous vapour-liquid critical curve stretching between the critical points of the pure components, the only difference being that in type II phase behaviour an additional liquid-liquid (LL) critical curve intersects a liquid-liquid-vapour three-phase (LLV) equilibrium curve in an upper critical endpoint (UCEP).

In order to calculate the critical curve, the experimental vapour-liquid equilibrium data from [16] were firstly correlated by GEOS/2PCMR and GEOS3C/2PCMR models at each temperature.

Figure 1 illustrates the comparisons of the experimental data [16] at the four available temperatures $(313.15,323.15,333.15$, and $343 \mathrm{~K})$ with the correlation results by GEOS/2PCMR and GEOS3C/2PCMR, as well as by $\mathrm{SRK} / 2 \mathrm{PCMR}$ and PR/2PCMR. All models behave similarly, the experimental data are well reproduced, with an overestimation of the critical region. It can be noticed that mixture critical points calculated SRK and PR are overestimated by about 15 bar while the critical pressure by GEOS and GEOS3C is overestimated with less than 8 bar (see Figure 2). However, all models fail to 
reproduce correctly the critical compositions which are underestimated compared with the experimental ones. In Figure 3 are shown the average values of the average absolute deviations in bubble-point pressures (AADP, \%) for each model. Although all models have similar performances, the smallest errors are obtained by GEOS3C. The optimized binary interaction parameters (BIPs) for GEOS and GEOS3C are presented in Table 2 together with the average absolute deviations in bubble-point pressures (AADP, \%), and the average absolute deviations in the vapour-phase compositions (AADY, \%), which are calculated by the equations:

$$
\begin{aligned}
& A A D P(\%)=\frac{1}{N_{\exp }} \sum_{i=1}^{N_{\text {exp }}}\left|\frac{P_{i}^{\exp }-P_{i}^{\text {calc }}}{P_{i}^{\exp }}\right| \times 100 \\
& A A D Y(\%)=\frac{1}{N_{\exp }} \sum_{i=1}^{N_{\text {exp }}}\left|Y_{i}^{\exp }-Y_{i}^{\text {calc }}\right| \times 100
\end{aligned}
$$

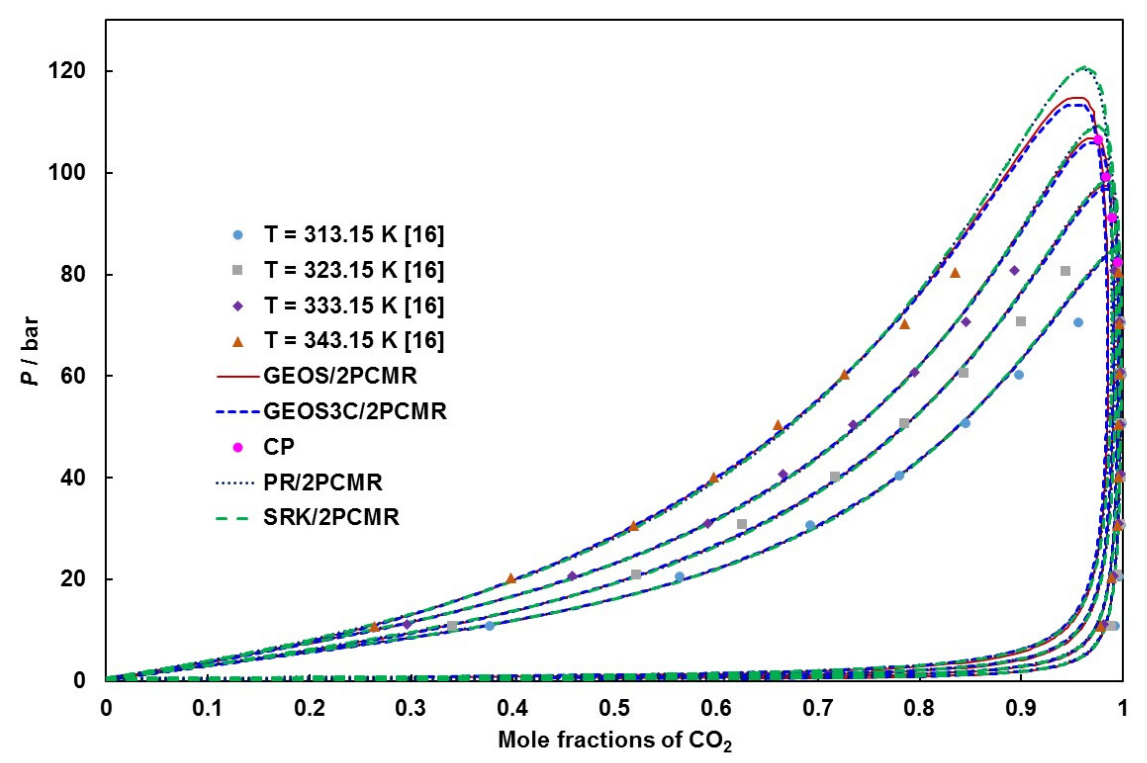

Figure 1. Comparison of literature VLE data [16] and correlations by GEOS (red solid line), GEOS3C (dashed blue line), SRK (dashed green lines), and PR (dotted dark blue line) EoSs for carbon dioxide (1) + 1,2-DME (2) system. $\mathrm{CP}$ stands for critical point of the mixture. 
PHASE BEHAVIOUR CALCULATIONS FOR THE CARBON DIOXIDE + 1,2-DIMETHOXYETHANE BINARY SYSTEM WITH A CUBIC EQUATION OF STATE

Table 2. Optimized binary interaction parameters $\left(k_{12}, l_{12}\right)$

\begin{tabular}{c|c|c|c|c|c}
\hline EoS/Mixing rule & $T / \mathrm{K}$ & $k_{12}$ & $l_{12}$ & $A A D P / \%$ & $A A D Y / \%$ \\
\hline & 313.15 & -0.2693 & -0.0263 & 3.66 & 0.35 \\
GEOS/2PCMR & 323.15 & -0.2603 & -0.0118 & 4.21 & 0.53 \\
& 333.15 & -0.2580 & -0.0131 & 2.67 & 0.89 \\
& 343.15 & -0.2260 & 0.0111 & 2.71 & 1.54 \\
\hline & 313.15 & -0.2684 & -0.0241 & 3.51 & 0.36 \\
GEOS3C/2PCMR & 323.15 & -0.2584 & -0.0094 & 3.92 & 0.56 \\
& 333.15 & -0.2553 & -0.0104 & 2.47 & 0.97 \\
& 343.15 & -0.2234 & 0.0134 & 2.46 & 1.70 \\
\hline
\end{tabular}

As the values of optimized BIPs are very similar for GEOS and GEOS3C models, the critical curve was calculated in this study by GEOS EoS. It must be remarked that each set of binary interaction parameters obtained from the correlations at each of the four available temperatures leads to a critical curve.

Therefore, the values of the optimized binary interaction parameters were averaged for GEOS model and then were used to calculate the critical curve for the carbon dioxide (1) + 1,2-DME (2) binary system.

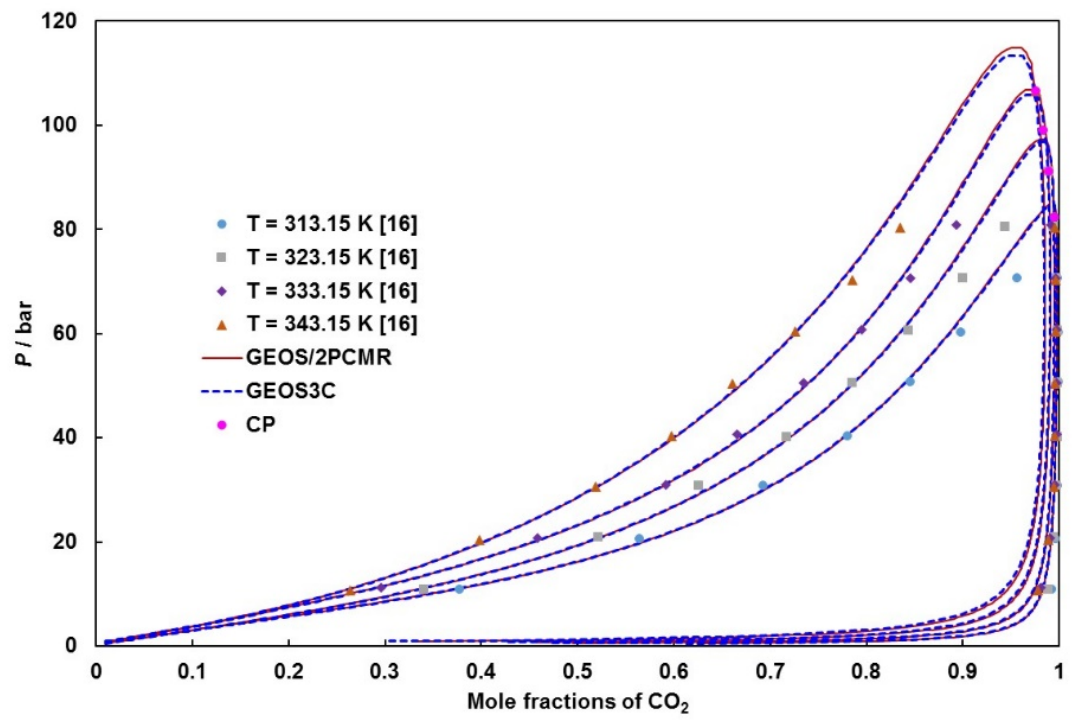

Figure 2. Comparison of literature VLE data [16] and correlations by GEOS (red solid line) and GEOS3C (dashed blue line) models for carbon dioxide (1) + 1,2-DME (2) system. 


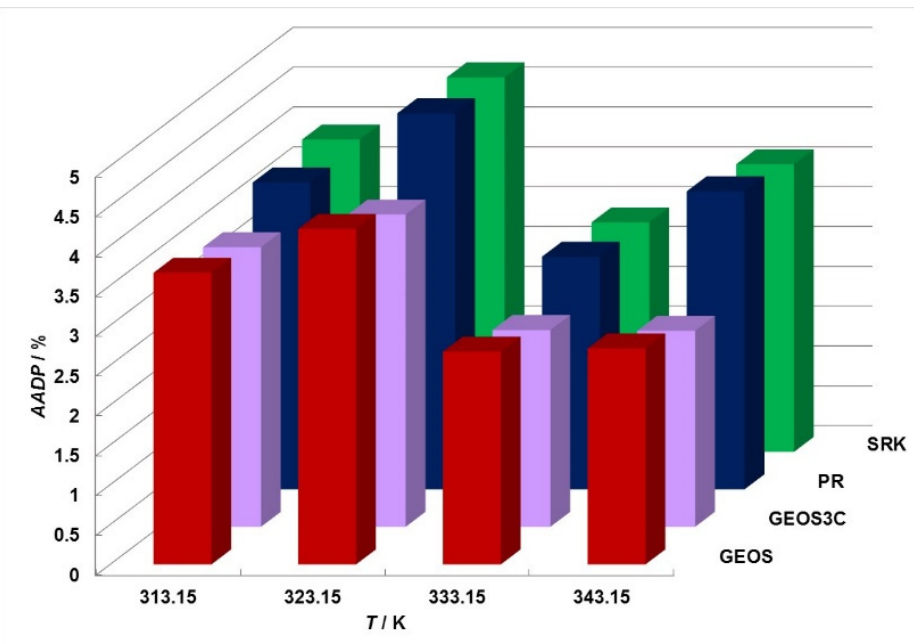

Figure 3. Average absolute deviations in bubble-point pressures (AADP, \%) for GEOS (dark red), GEOS3C (purple), PR (dark blue), and SRK (green) models at different temperatures.

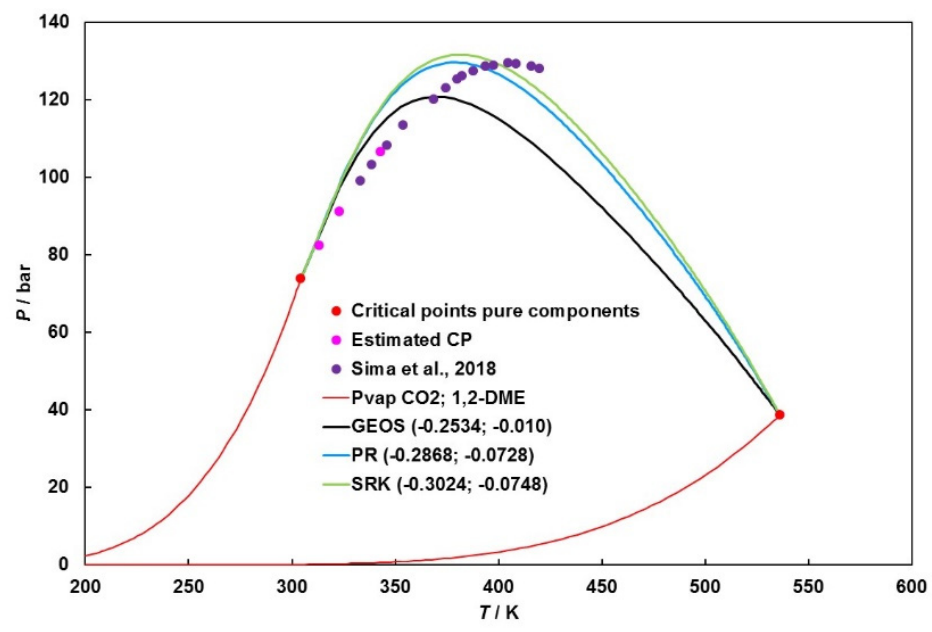

Figure 4. $P-T$ fluid phase diagram for $\mathrm{CO}_{2}(1)+1,2$-DME (2) system: ( $\bullet$, critical points of pure components [29]; $(\bullet, \bullet)$, critical curve [16]; $(-)$, vapour pressure curves; $(-)$, critical curve calculated by GEOS $\left(k_{12}=-0.2534 ; l_{12}=-0.0100 ;(-)\right.$, critical curve calculated by SRK $\left(k_{12}=-0.3024 ; l_{12}=-0.0748\right) ;(-)$, critical curve calculated by PR $\left(k_{12}=-0.2868 ; l_{12}=-0.0728\right)$. 
Table 3. Binary interaction parameters $\left(k_{12}, l_{12}\right)$

\begin{tabular}{|l|c|c|c|c|}
\hline Model & \multicolumn{2}{|c|}{ Average BIPs } & \multicolumn{2}{c|}{ Modified BIPs $^{\mathrm{a}}$} \\
\hline & $k_{12}$ & $l_{12}$ & $k_{12}$ & $l_{12}$ \\
\hline GEOS/2PCMR & -0.2534 & -0.0100 & -0.0140 & -0.0010 \\
\hline PR/2PCMR & -0.2868 & -0.0728 & 0.0050 & -0.0500 \\
\hline SRK/2PCMR & -0.3024 & -0.0748 & 0.0100 & -0.0750 \\
\hline
\end{tabular}

aModified binary interaction parameters are obtained by a trial and error procedure

Table 3 summarizes the average values of BIPs for GEOS, SRK, and PR models. The calculations are compared with the experimental critical data [16] in Figure 4.

It can be seen that the critical curves calculated with the average values of BIPs resulted from correlations are not in good agreement with experimental critical curve. While GEOS leads to a critical pressure maximum (CPM) smaller than the experimental one, PR and SRK are slightly overestimate its value. Even though all three models are reproducing relatively well the CPM, the corresponding critical temperatures are much underestimated.

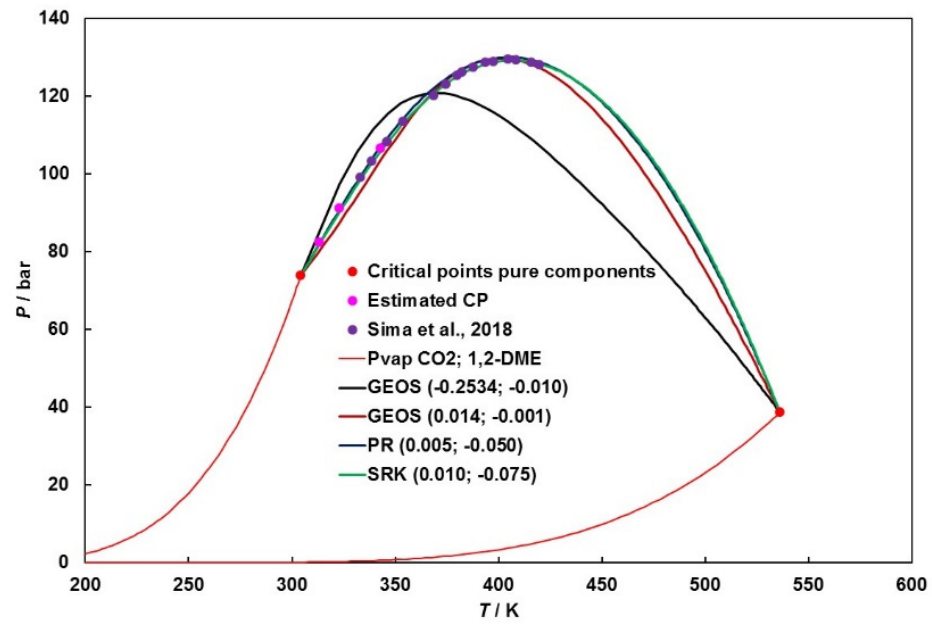

Figure 5. $P-T$ fluid phase diagram for $\mathrm{CO}_{2}(1)+1,2$-DME (2) system: ( $\bullet$, critical points of pure components [29]; $(\bullet, \bullet)$, critical curve [16]; $(-)$, vapour pressure curves; $(-)$, critical curve by GEOS $\left(k_{12}=-0.2534 ; l_{12}=-0.0100\right)$; $(-)$, critical curve by GEOS $\left(k_{12}=0.0140 ; l_{12}=-0.0010\right) ;(-)$, critical curve by SRK $\left(k_{12}=0.0100\right.$; $\left.l_{12}=-0.0750\right) ;(-)$, critical curve by PR $\left(k_{12}=0.0050 ; l_{12}=-0.0500\right)$. 
In Figure $\mathbf{5}$ are presented the predictions of the critical by GEOS, as well as by PR and SRK [16]. The predictions by GEOS, PR, and SRK are almost overlapped, meaning that their CPMs and maximum critical temperatures are comparable. The CPMs predicted by all three models are in very good agreement with the experimental one, the highest difference is $\sim 0.5$ bar (PR). The maximum critical temperature is also very well predicted by all equations and the highest difference is $\sim 4 \mathrm{~K}$ (GEOS), compared with the experimental value.

Although the predictions by these unique sets lead to small changes in critical pressures and temperatures compared with the experimental critical data, when plotting the critical pressures (Figure 6) or critical temperatures (Figure 7) against critical compositions, it can be remarked that the differences are exceeding 0.1 in molar composition.

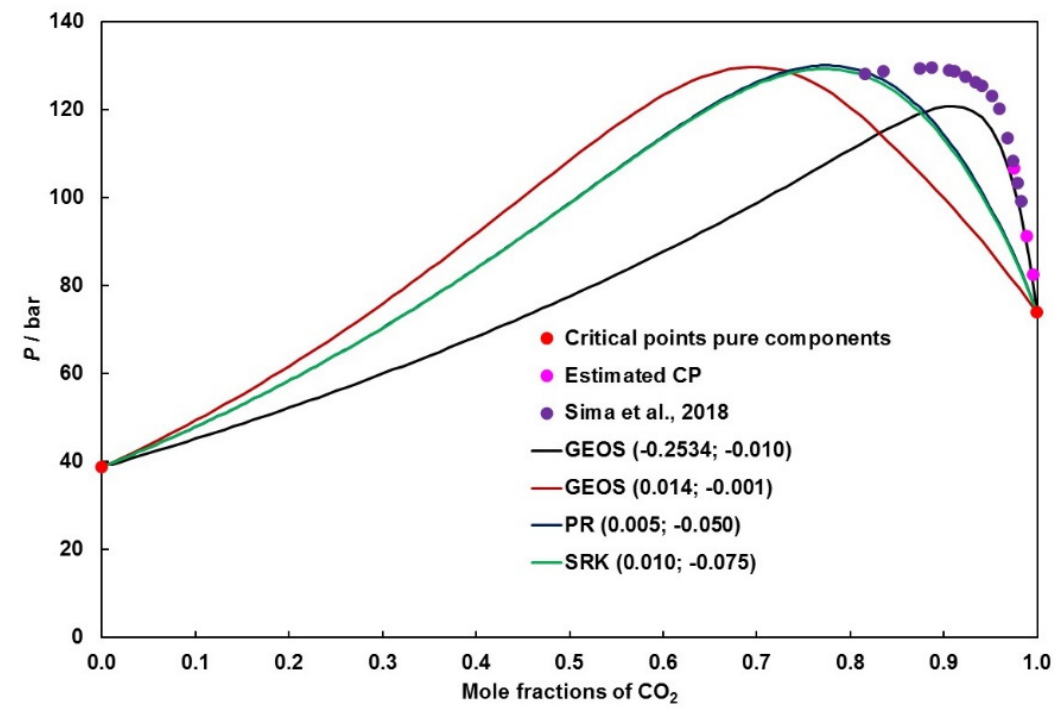

Figure 6. $P-x$ projection of the phase diagram for carbon dioxide (1) + 1,2-DME (2) system: $(\bullet, \bullet)$, literature data [16] and calculations by $(-)$, GEOS $\left(k_{12}=-0.2534\right.$; $\left.l_{12}=-0.0100\right) ;(-)$, GEOS $\left(k_{12}=0.0140 ; l_{12}=-0.0010\right) ;(-)$, SRK $\left(k_{12}=0.0100\right.$; $\left.l_{12}=-0.0750\right) ;(-), \operatorname{PR}\left(k_{12}=0.0050 ; l_{12}=-0.0500\right)$.

Consequently, we used a similar semi-predictive approach as in previous studies $[8,16]$ and we obtained an unique set of binary interaction parameters for GEOS that represent very well the experimental critical curve. This set of BIPs (Table 3, "Modified BIPs") was estimated by a trial and error procedure, which yield coordinates of critical data closer to the experimental ones. 
PHASE BEHAVIOUR CALCULATIONS FOR THE CARBON DIOXIDE + 1,2-DIMETHOXYETHANE BINARY SYSTEM WITH A CUBIC EQUATION OF STATE

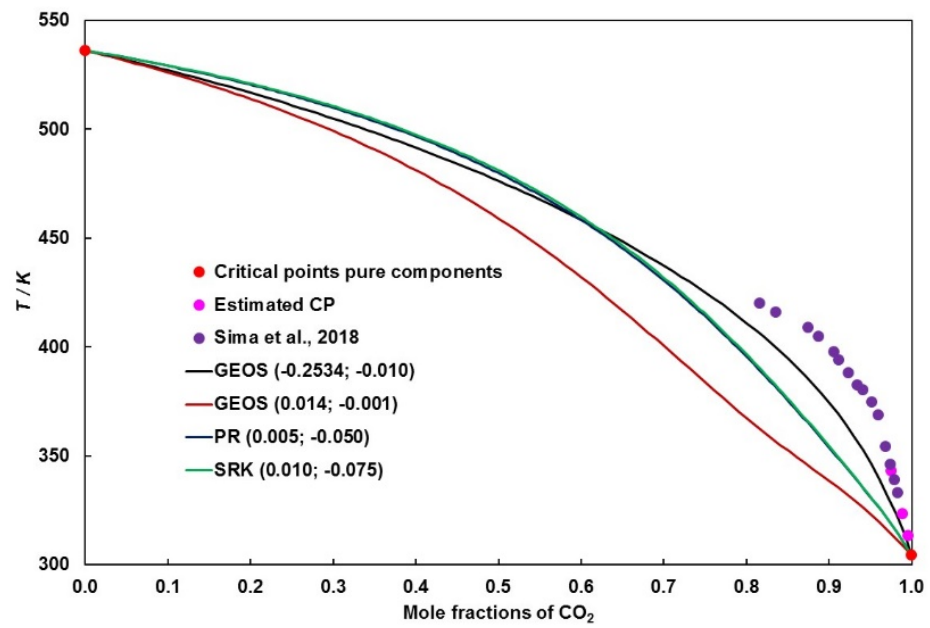

Figure 7. $T-x$ projection of the phase diagram for carbon dioxide (1) + 1,2-DME (2) system: $(\bullet, \bullet)$, critical experimental data [16] and calculations by

$(-)$, GEOS $\left(k_{12}=-0.2534 ; l_{12}=-0.0100\right) ;(-)$, GEOS $\left(k_{12}=0.0140 ; l_{12}=-0.0010\right)$ $(-)$, SRK $\left(k_{12}=0.0100 ; l_{12}=-0.0750\right) ;(-)$, PR $\left(k_{12}=0.0050 ; l_{12}=-0.0500\right)$.

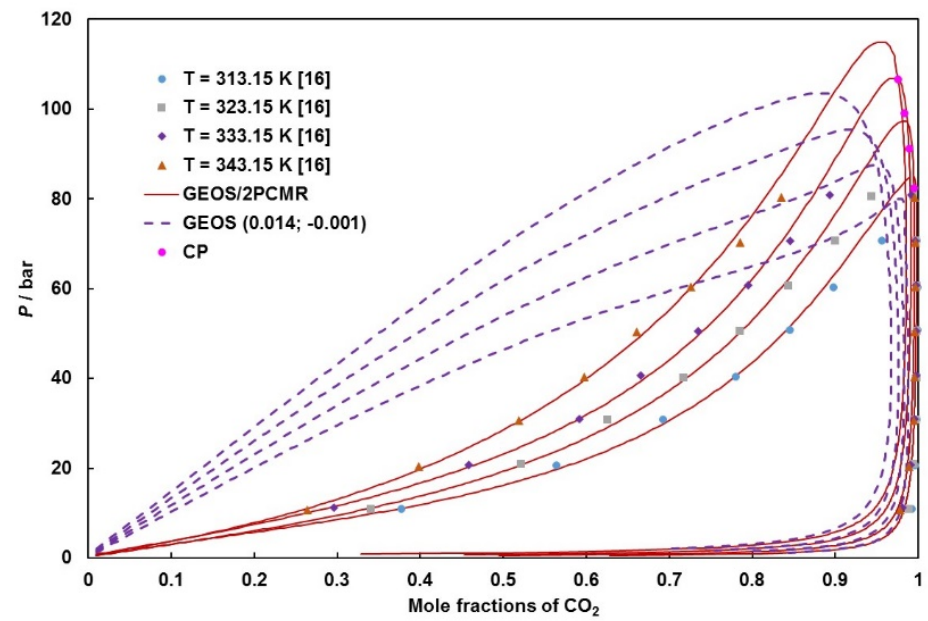

Figure 8. Comparison of correlations and predictions by GEOS for the $\mathrm{CO}_{2}(1)+$ 1,2-DME (2) system: symbols are the experimental data [16], red solid lines are the correlations, and purple dashed lines are the semi-predictions (BIPs from Table 3). 


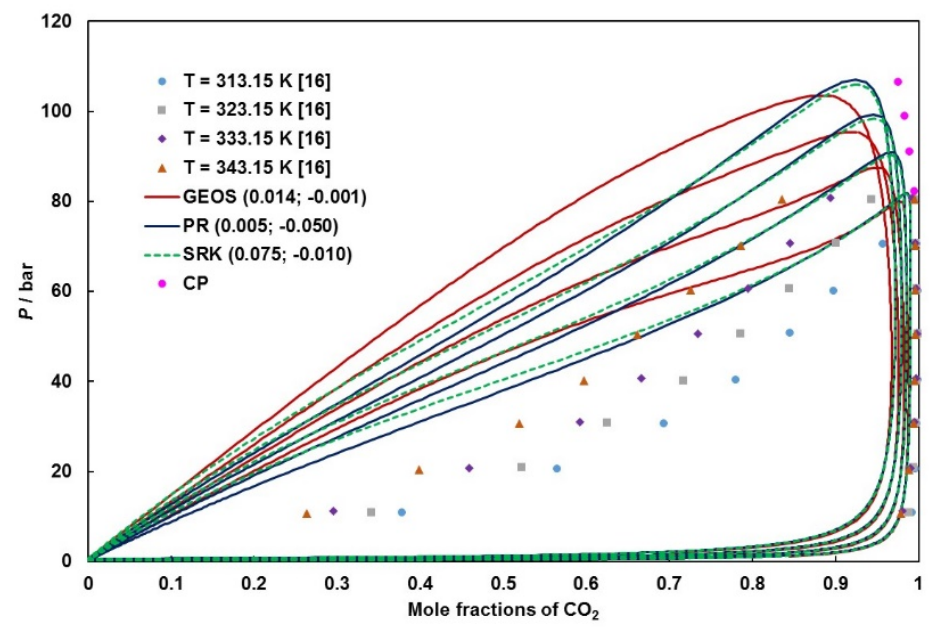

Figure 9. Comparison of experimental data and predictions by GEOS, PR, and SRK EoSs for the carbon dioxide (1) + 1,2-DME (2) system:

symbols are the experimental data [16], and the lines are the semi-predictions

with the modified parameters in Table 3 (dark red solid lines, GEOS; dark blue solid line, PR; dashed green line, SRK).

This difference is very well noticed when representing the model results in the pressure-composition diagram. In Figure 8 are presented the correlations and predictions by GEOS model, while in Figure 9 are compared the predictions by GEOS, PR, and SRK. It can be seen that the critical pressure of each isotherm is well reproduced, but the compositions, especially the liquid ones, are not.

\section{CONCLUSIONS}

The GEOS and GEOS3C, as well as PR and SRK equations of state coupled with classical quadratic van der Waals mixing rules were used to model the phase behaviour of the carbon dioxide (1) + 1,2-DME (2) binary system. The aforementioned models reproduce very well the $P-T$ critical curve when using a semi-predictive approach, but fail to reproduce well the critical compositions.

The topology of phase behaviour is very well predicted, taking into account the relatively simple models and modelling procedure. 
PHASE BEHAVIOUR CALCULATIONS FOR THE CARBON DIOXIDE + 1,2-DIMETHOXYETHANE BINARY SYSTEM WITH A CUBIC EQUATION OF STATE

\section{ACKNOWLEDGMENTS}

„This work was supported by a grant of Ministry of Research and Innovation, CNCS - UEFISCDI, project number PN-III-P4-ID-PCE-20160629, within PNCDI III".

\section{REFERENCES}

1. https://www.epa.gov/ghgemissions/overview-greenhouse-gases, accessed July 2019

2. IPCC, Climate Change 2014: Mitigation of Climate Change: Contribution of Working Group III to the Fifth Assessment Report of the Intergovernmental Panel on, Cambridge University Press, 2014

3. M.T. Mota-Martinez; J.P. Hallett; N. Mac Dowell, Sustain. Energ. Fuels, 2017, 1, 2078-2090

4. https://www.iea.org/geco/emissions/, accessed July 2019

5. M. Bui; M. Fajardy; N. Mac Dowell; Fuel, 2018, 213, 164-175

6. C. Secuianu; V. Feroiu; D. Geană; J. Chem. Eng. Data, 2010, 55 (10), 42554259

7. S. Sima; J.M. Milanesio; J.I. Ramello; M. Cismondi; C. Secuianu; V. Feroiu; D. Geană; J. Chem. Thermodyn., 2016, 93, 374-385

8. A.V. Crişciu; S. Sima; A.-S. Deaconu; A. Chirilă; D. Deaconu; C. Secuianu; V. Feroiu; Rev. Chim.-Bucharest, 2016, 67 (10), 1984-1989

9. S. Sima; S. Ionită; C. Secuianu; V. Feroiu; D. Geană; J. Chem. Eng. Data, 2018, 63 (4), 1109-1122

10. S. Sima; R.C. Racoviţă; C. Dincă; V. Feroiu; C. Secuianu; Univ. Politeh. Buchar. Sci. Bull.-Ser. B-Chem. Mat. Sci., 2017, 79 (4), 11-24

11. C. Secuianu; V. Feroiu; D. Geană; Fluid Phase Equilib., 2016, 428, 62-75

12. S. Secuianu; S. Ioniţă; V. Feroiu; D. Geană; J. Chem. Thermodyn., 2016, 93, 360-373

13. S. Ioniţă; C. Secuianu; V. Feroiu; D. Geană; Univ. Politeh. Buchar. Sci. Bull.Ser. B-Chem. Mat. Sci., 2015, 77 (1), 31-40

14. S. Sima; C. Secuianu; V. Feroiu; D. Geană; Cent. Eur. J. Chem., 2014, 12 (9), 953-961

15. S. Sima; C. Secuianu; V. Feroiu; D. Geană; Cent. Eur. J. Chem., 2014, 12 (9), 893-900

16. S. Sima; C. Secuianu; V. Feroiu; Fluid Phase Equilib., 2018, 458, 47-57

17. C. Secuianu; J. Qian; R. Privat; J.-N. Jaubert; Ind. Eng. Chem. Res., 2012, 51, 11284-11293

18. J. Gujt, H. Dominguez; S. Sokolowski; O. Pizio; Cond. Matt. Phys., 2017, 20, $1-14$ 
19. A. Jänes; J. Eskusson; T. Thomberg; T. Romann; E. Lust; J. Energy Chem., 2016, 25, 609-614.

20. D. Geană; Rev. Chim. (Bucharest), 1986, 37, 303-309

21. D. Geană; Rev. Chim. (Bucharest), 1986, 37, 951-959

22. D. Geană; Rev. Chim. (Bucharest), 1987, 38, 975-979

23. D. Geană; V. Feroiu; Fluid Phase Equilib., 2000, 174, 51-68

24. D. Geană; V. Feroiu; Ecuaţii de stare. Aplicaţii la echilibre de faze, Ed. Tehnică: Bucharest, Romania, 2000

25. C. Secuianu; V. Feroiu; D. Geană; J. Supercrit. Fluid., 2008, 47 (2), 109-116

26. D. Geană; L. Rus; Phase equilibria database and calculation program for pure components systems and mixtures, in Proc. Romanian Int. Conf. Chem. Chem. Eng. (RICCCE XIV), Bucharest, Romania, 2005; Volume 2, pp.170-178

27. R.A. Heidemann; A. M. Khalil; AIChE J., 1980, 26, 769-779

28. R. Stockfleth; R. Dohrn; Fluid Phase Equilib., 1998, 145, 43-52

29. Evaluated Standard Thermophysical Property Values, DIPPR Project 801 full version, Brigham Young University, Provo Utah, 2005

30. P.H. van Konynenburg; R.L. Scott; Philos. Trans. R. Soc. Lond.-Ser. A, 1980, 298, 495-540

31. R. Privat; J.-N. Jaubert; Chem. Eng. Res. Des., 2013, 91, 1807-1839 